\title{
Improving continence after prostatectomy: integrating magnetic resonance imaging with the Retzius-sparing approach
}

\author{
Nirmish Singla \\ Urology Service, Department of Surgery, Memorial Sloan Kettering Cancer Center, New York, NY, USA \\ Correspondence to: Nirmish Singla, MD, MSCS. Urology Service, Department of Surgery, Memorial Sloan Kettering Cancer Center, 1275 York \\ Avenue, New York, NY 10065, USA. Email: nirmish@gmail.com. \\ Provenance and Peer Review: This article was commissioned by the Editorial Office, Translational Andrology and Urology. The article did not undergo \\ external peer review. \\ Comment on: $\mathrm{Li} \mathrm{Y,} \mathrm{Li} \mathrm{W,} \mathrm{Lu} \mathrm{W,} \mathrm{et} \mathrm{al.} \mathrm{Association} \mathrm{of} \mathrm{preoperative} \mathrm{urethral} \mathrm{parameters} \mathrm{on} \mathrm{magnetic} \mathrm{resonance} \mathrm{imaging} \mathrm{and} \mathrm{immediate} \mathrm{recovery} \mathrm{of}$ \\ continence following Retzius-sparing robot-assisted radical prostatectomy. Transl Androl Urol 2020;9:501-9.
}

Submitted Dec 26, 2019. Accepted for publication Dec 30, 2019.

doi: $10.21037 /$ tau.2020.01.08

View this article at: http://dx.doi.org/10.21037/tau.2020.01.08

Persistent and bothersome urinary leakage following radical prostatectomy can be a devastating quality of life issue for a subset of men undergoing surgical treatment for localized prostate cancer. Although management strategies for postprostatectomy incontinence (PPI) have been quite effective, including both conservative and surgical (male urethral sling or artificial urinary sphincter) approaches, many investigators have explored ways to mitigate this issue altogether. Several risk factors predicting the development of PPI have been described and include preoperative comorbidities, patient anatomical features, and intraoperative techniques (1). The ability to more accurately predict PPI in patients contemplating local treatment options for prostate cancer can enable a more effective means of counseling them on their individualized risk of developing post-surgical incontinence.

Within the past decade, the technique of Retzius-sparing radical prostatectomy was introduced as a means to maximize functional outcomes by attempting to preserve anterior structures (including the neurovascular bundles, Aphrodite's veil, endopelvic fascia, the Santorini plexus, and pubourethral ligaments, among others) via a purely intrafascial, posterior dissection approach (2). Compared to conventional roboticassisted radical prostatectomy (RARP), the Retzius-sparing approach (RS-RARP) has been shown to correlate with hastened recovery of continence across multiple studies $(3,4)$. However, the appropriate candidacy for this approach is still evolving, given the potentially higher risk of positive surgical margins (4), which may be related to the proposed learning curve of mastering this technique.

Aside from alternative surgical approaches, prostate cancer has also witnessed a diagnostic and therapeutic shift over the last decade with the advent of multiparametric magnetic resonance imaging (MRI). In addition to guiding targeted biopsies of the prostate, MRI can hold tremendous utility in surgical planning by predicting adverse pathological features such as extracapsular extension or seminal vesical invasion (5) and by delineating anatomic features such as a sizable intravesical prostatic lobe. In addition to predicting pathology, MRI may hold additional value in predicting functional outcomes in patients. Many groups have investigated various MRI anatomic parameters and reported that a shorter membranous urethral length (MUL) and longer pubic symphysis-prostate apex length (PAL) on preoperative MRI may be associated with higher rates of PPI (6-9). Minimal residual membranous urethral length (mRUL) was also recently introduced as a parameter representing the minimal intact portion of the membranous urethra during RARP by capturing the distance between the lower margins of the puboperinealis and bulbospongiosus muscles (10). As with MUL, longer mRUL was found to be significantly associated with improved rates of post-surgical continence.

The novelty of the current work by Li et al. lies in its assessment of preoperative MRI features in predicting early continence recovery specifically in the setting of RS-RARP (11). Although limited by a retrospective, single-institution, singlesurgeon approach, the authors evaluated several preoperative MRI parameters including mRUL, periurethral sphincter complex thickness, urethral wall thickness, levator ani muscle thickness, and obturator internus muscle thickness. They were able to identify a subset of RS-RARP patients that experienced early PPI and found that, consistent with conventional RARP, longer mRUL was associated with 
early return of continence after RS-RARP, while none of the other MRI measurements were significantly correlated with continence outcomes. This study mirrors another recently published by the same group, in which the authors reported on significant clinical predictors for early return of continence after RS-RARP, which included prostate volume and preoperative lower urinary tract symptoms (12).

Whether the learning curve for RS-RARP or other unmeasured confounders played an influential role in the continence outcomes and whether long-term continence outcomes are significantly affected by these parameters remain unknown. Furthermore, appropriate patient selection for undergoing the RS-RARP technique may also warrant further investigation. Nonetheless, the work by $\mathrm{Li}$ et al. is an important contribution to an evolving body of literature and will undoubtedly hold value in counseling patients regarding their functional outcomes after RARP.

\section{Acknowledgments}

Funding: None.

\section{Footnote}

Conflicts of Interest: The author has completed the ICMJE uniform disclosure form (available at http://dx.doi. org/10.21037/tau.2020.01.08). The author has no conflicts of interest to declare.

Ethical Statement: The author is accountable for all aspects of the work in ensuring that questions related to the accuracy or integrity of any part of the work are appropriately investigated and resolved.

Open Access Statement: This is an Open Access article distributed in accordance with the Creative Commons Attribution-NonCommercial-NoDerivs 4.0 International License (CC BY-NC-ND 4.0), which permits the noncommercial replication and distribution of the article with the strict proviso that no changes or edits are made and the original work is properly cited (including links to both the formal publication through the relevant DOI and the license). See: https://creativecommons.org/licenses/by-nc-nd/4.0/.

\section{References}

1. Singla N, Singla AK. Post-prostatectomy incontinence: Etiology, evaluation, and management. Turk J Urol 2014;40:1-8.

2. Galfano A, Ascione A, Grimaldi S, et al. A new anatomic approach for robot-assisted laparoscopic prostatectomy: a feasibility study for completely intrafascial surgery. Eur
Urol 2010;58:457-61.

3. Lee J, Kim HY, Goh HJ, et al. Retzius Sparing RobotAssisted Radical Prostatectomy Conveys Early Regain of Continence over Conventional Robot-Assisted Radical Prostatectomy: A Propensity Score Matched Analysis of 1,863 Patients. J Urol 2020;203:137-44.

4. Checcucci E, Veccia A, Fiori C, et al. Retzius-sparing robot-assisted radical prostatectomy vs the standard approach: a systematic review and analysis of comparative outcomes. BJU Int 2020;125:8-16.

5. Morlacco A, Sharma V, Viers BR, et al. The Incremental Role of Magnetic Resonance Imaging for Prostate Cancer Staging before Radical Prostatectomy. Eur Urol 2017;71:701-4.

6. Fukui S, Kagebayashi Y, Iemura Y, et al. Preoperative MRI Parameters Predict Urinary Continence after Robot-Assisted Laparoscopic Prostatectomy in Prostatic Cancer Patients. Diagnostics (Basel) 2019. doi: 10.3390/ diagnostics9030102.

7. Kim LHC, Patel A, Kinsella N, et al. Association Between Preoperative Magnetic Resonance Imaging-based Urethral Parameters and Continence Recovery Following Robotassisted Radical Prostatectomy. Eur Urol Focus 2019. [Epub ahead of print].

8. Kim M, Park M, Pak S, et al. Integrity of the Urethral Sphincter Complex, Nerve-sparing, and Long-term Continence Status after Robotic-assisted Radical Prostatectomy. Eur Urol Focus 2019;5:823-30.

9. Matsushita K, Kent MT, Vickers AJ, et al. Preoperative predictive model of recovery of urinary continence after radical prostatectomy. BJU Int 2015;116:577-83.

10. Satake Y, Kaiho Y, Saito H, et al. Estimated Minimal Residual Membranous Urethral Length on Preoperative Magnetic Resonance Imaging Can Be a New Predictor for Continence After Radical Prostatectomy. Urology 2018;112:138-44.

11. Li Y, Li W, Lu W, et al. Association of preoperative urethral parameters on magnetic resonance imaging and immediate recovery of continence following Retziussparing robot-assisted radical prostatectomy. Transl Androl Urol 2020;9:501-9.

12. Qin H, Qiu X, Ma H, et al. Predictors for immediate recovery of continence following Retzius-sparing robotassisted radical prostatectomy: a case-control study. Int Urol Nephrol 2019;51:825-30.

Cite this article as: Singla N. Improving continence after prostatectomy: integrating magnetic resonance imaging with the Retzius-sparing approach. Transl Androl Urol 2020;9(2):151-152. doi: 10.21037/tau.2020.01.08 